\title{
Analysis on green innovation cooperation of government, industry, University and Research Institute from the perspective of evolutionary game under the conditions of informationization
}

\author{
Zhaoqian Duan ${ }^{1, a *}$ WeiJian Zhu ${ }^{2}$ Dan Bai ${ }^{3}$ \\ ${ }^{1}$ School of Liaoning, Dalian University Dalian, China \\ ${ }^{2}$ School of Liaoning, Dalian University Dalian, China \\ ${ }^{3}$ School of Liaoning, Dalian University Dalian, China
}

\begin{abstract}
Under the new normal of the economy where informatization and industrialization are deeply integrated, the balanced development of economy and ecology is increasingly important. How to promote the development of green innovation through policy means under the conditions of informatization and realize the balanced development of economy and ecology is a key issue for the government.. The development of informatization has facilitated the dissemination of information, knowledge, and funds between enterprises and academic institutions, promoted the establishment of mutual trust and cooperation between enterprises and academic institutions, and improved the efficiency of green technology knowledge conversion. Based on the evolutionary game theory, this paper constructs a game model of green innovation cooperation between government, industry, University and Research Institute, analyzes the strategy selection of government, enterprise and university research side in the game process, and studies the stability of green innovation cooperation of government, industry, University and Research Institute. The analysis results show that default fines, excess income, government subsidies, etc. have an impact on the benefits of green innovation, and on this basis, relevant policy recommendations are put forward for government-industry-university-research green innovation cooperation under the conditions of informatization.
\end{abstract}

\section{Introduction}

Since the reform and opening up, China's economy has achieved unprecedented development. However, while the economy is developing rapidly, problems such as waste of resources and environmental pollution have become increasingly prominent, which has severely damaged economic development and people's lives. Green innovation can reduce the generation of waste and pollutants while saving resources, which is consistent with the essence of building a harmonious society and taking the road of sustainable development.At present, due to the high barriers to green innovation and the high cost of research and development, Chinese enterprises have a negative attitude [1], which makes it more difficult for enterprises to carry out green innovation. Cao Xia and Zhang Lupeng [2] constructed a tripartite game model of government, enterprises, and consumers, and believed that low-intensity government publicity on environmental protection and appropriate innovation incentives and compensations can promote green innovation in enterprises. Xu Jianzhong [3] believed that enterprises will choose different green innovation models, mainly affected by environmental regulations such as government green innovation subsidies and carbon taxes. A single environmental regulation cannot stimulate more green innovation, and government subsidies can produce better results when governing the environment [4].

Etzkowitz $\mathrm{H}$. first proposed in the research that in an innovation system, the enterprise is the initiator of innovation activities, the academic research institute is the organizer of innovation activities, and the manager of government organizers. The three are independent and coordinate with each other to form Dynamic triple helix structure [5]. As a guide and a supervisor, the government can provide support and supervision to the green innovation cooperation between enterprises and academic research institutes, which is conducive to promoting the efficiency of green innovation. Cao Xia et al. [6] constructed a dynamic replication equation of the threeparty game of government, industry, academia, and research from three government approaches: government subsidy, government tax exemption, and government assessment. Research has proved that government governance can affect the collaborative development of industry-university-research cooperation collaborative innovation. The research by Zang Xinyu and Ma Yonghong [7] shows that the reward and punishment mechanism formulated by the government has a positive impact on the formation of industry-university-research cooperation, but the reward and punishment should be controlled to a certain extent.

The evolutionary game theory that originated from the 
theory of biological evolution assumes bounded rationality as the premise, and believes that a certain size of game group through continuous revision of its own strategy in the repeated game process, makes all game parties tend to a certain stable state, this stable state is called evolutionary stable strategy (ESS) [8]. Evolutionary game theory provides a new theoretical perspective for the discussion of the green innovation game process of government, industry, university and research [9]. The government, industry, university and research institute green innovation collaboration is a dynamic game process.

\section{The establishment of the green innovation evolution game model of government, industry, university and research institute}

\subsection{Model assumption}

Hypothesis 1: Game subject. In the research of this paper, the school and scientific research institutions are unified as the academic research side for analysis, that is, the game subject we only consider the government, enterprises and academic research side.

Hypothesis 2: Strategy selection.In the process of cooperation, the players can choose to cooperate or not to cooperate according to their actual situation.

Hypothesis 3: Cooperation costs. The government needs to build a basic public platform, formulate relevant laws and regulations to encourage, supervise the cooperation process and other activities. The total cost incurred is G1. The total cost of the resources invested by the enterprise and the academic research side in the process of participating in green innovation is $\mathrm{C}$, and is allocated according to the ratio of $t$ and 1-t. When one of the enterprise or the academic research party breaches the contract, the breaching party needs to separately invest $\mathrm{C} 1$ and $\mathrm{C} 2$ to continue the green innovation. The resource cost already invested by both parties at the time of the breach is $\mathrm{C} 0$. When the government chooses to participate in green innovation, the support and supervision provided by

Table1. Government participation in government, industry, university and research payment matrix

\begin{tabular}{|c|c|c|c|}
\hline & & \multicolumn{2}{|c|}{ university and research } \\
\hline \multirow{2}{*}{ enterprise } & Cooperation & $\begin{array}{c}\text { R1-G1-G2,R2+aR-(1- } \alpha) t(C-S), R 3+(1-a) R-(1-t)(C- \\
\text { S)+G2 }\end{array}$ & $\mathrm{R} 1-\mathrm{G} 1, \mathrm{R} 2-\mathrm{t}(\mathrm{C} 0-\mathrm{S})+\mathrm{F}, \mathrm{R} 3+\mathrm{L}-(1-\mathrm{t}) \mathrm{C} 0-\mathrm{C} 2-\mathrm{F}$ \\
\hline & Uncooperative & R1-G1-G2,R2+L-tC0-(1- $\alpha) \mathrm{C} 1-\mathrm{F}, \mathrm{R} 3-(1-\mathrm{t})(\mathrm{C} 0-\mathrm{S})+\mathrm{G} 2+\mathrm{F}$ & R1-G1,R2,R3 \\
\hline \multicolumn{4}{|c|}{ ent does not participate in the government, industry, education and rese } \\
\hline & & Cooperation & Uncooperative \\
\hline \multirow{2}{*}{ enterprise } & Cooperation & $\mathrm{bR} 1, \mathrm{R} 2+\mathrm{aR}-(1-\alpha) \mathrm{tC}, \mathrm{R} 3+(1-\mathrm{a}) \mathrm{R}-(1-\mathrm{t}) \mathrm{C}$ & $\mathrm{bR} 1, \mathrm{R} 2-\mathrm{tC} 0+\mathrm{F}, \mathrm{R} 3+\mathrm{L}-(1-\mathrm{t}) \mathrm{C} 0-\mathrm{C} 2-\mathrm{F}$ \\
\hline & Uncooperative & bR1,R2+L-tC0-(1- $\alpha) C 1-F, R 3-(1-t) C 0+F$ & bR1,R2,R3 \\
\hline
\end{tabular}

the government will reduce the cost of resources invested by enterprises and academic research institutes, assuming that the amount of cost reduction is recorded as $\mathrm{S}$.

Hypothesis 4: Cooperation income. The initial income of enterprises and academic research institutes participating in political, industrial, academic, and research cooperation for green innovation are R2 and R3, respectively. When the enterprise and academic research institutes participate at the same time, additional income of $\mathrm{R}$ will be generated. Extra income. When the enterprise or the academic research side conducts green innovation alone, the income obtained is L. The government participates in the cooperation between the enterprise and the academic research party to obtain the income of R1. Use $b$ (the value of $b$ is between $0-1$ ) to indicate the proportion of the income that can be obtained when the government does not participate in the cooperation, when the government does not participate in the cooperation. The gain obtained is $\mathrm{bR} 1$. In order to encourage learning and research to actively cooperate with enterprises in green innovation, the government gives G2 financial support to those actively participating in green innovation cooperation.

Hypothesis 5: Green return coefficient. In this paper, in order to examine the benefits that green innovation brings to enterprises, we introduce a green profit coefficient $\alpha$, which represents the extent to which green innovation reduces the cost of enterprises.

Hypothesis 6: Penalty for breach of contract. Under the supervision of the government, in order to avoid the breach of the contract between the enterprise and the academic research side in the process of participating in green innovation cooperation, when one party defaults, the other party needs to pay $\mathrm{W}$ a fine.

\subsection{Construction of payment matrix}

Based on the above assumptions, we can obtain the payment matrix shown in Table 1 and Table 2.Assuming that their probability of choosing cooperation is $\mathrm{x}, \mathrm{y}$, and z.

\section{Analysis of evolutionary stability strategy}

\subsection{Construction of income expectation function}

According to the payment matrix, the expected return of the government participating in the game, the expected 
return of not participating in the game, and the average expected return are denoted by U11, U12, and U1, respectively:

$\mathrm{U} 11=\mathrm{yz}(\mathrm{R} 1-\mathrm{G} 1-\mathrm{G} 2)+\mathrm{y}(1-\mathrm{z})(\mathrm{R} 1-\mathrm{G} 1)+(1-\mathrm{y}) \mathrm{z}[\mathrm{R} 2+\mathrm{aR}-(1-$ $\alpha) \mathrm{tC}]+(1-\mathrm{y})(1-\mathrm{z})(\mathrm{R} 1-\mathrm{G} 1)=\mathrm{R} 1-\mathrm{G} 1-\mathrm{zG} 2$

$\mathrm{U} 12=\mathrm{yzbR} 1+\mathrm{y}(1-\mathrm{z}) \mathrm{bR} 1+(1-\mathrm{y}) \mathrm{zbR} 1+(1-\mathrm{y})(1-\mathrm{z}) \mathrm{bR} 1=\mathrm{bR} 1$

$\mathrm{U} 1=\mathrm{xU} 11+(1-\mathrm{x}) \mathrm{U} 12$

\subsection{Solve using copy dynamic equation}

The replication dynamics of the government, enterprises, and academic institutions can be obtained as equations:

$\mathrm{F}(\mathrm{x})=\mathrm{dx} / \mathrm{dt}=\mathrm{x}(\mathrm{U} 11-\mathrm{U} 1)=\mathrm{x}[\mathrm{U} 11-\mathrm{xU} 11-(1-\mathrm{x}) \mathrm{U} 12]=\mathrm{x}(1-$

$\mathrm{x})(\mathrm{U} 11-\mathrm{U} 12)=\mathrm{x}(1-\mathrm{x})[(1-\mathrm{b}) \mathrm{R} 1-\mathrm{G} 1-\mathrm{zG} 2]$

$(1-2 x)[(1-b) R 1-G 1-z G 2$

0

$\mathrm{y}(1-\mathrm{y})(1-\mathrm{z \alpha}) \mathrm{ts}$

$(1-2 \mathrm{y})\{\mathrm{F}-\mathrm{tC} 0+\mathrm{xts}-\mathrm{xz} \alpha \mathrm{ts}+\mathrm{z}[\mathrm{aR}-(1-\alpha)(\mathrm{tC}-\mathrm{C} 1)+2 \mathrm{t} \mathrm{C} 0-\mathrm{L}]\}$

$z(1-z)[G 2+(1-t) S]$

$\mathrm{z}(1-\mathrm{z})[(1-\mathrm{a}) \mathrm{R}-\mathrm{L}-(1-\mathrm{t})(\mathrm{C}-2 \mathrm{C} 0)+\mathrm{C} 2]$
$\mathrm{F}(\mathrm{y})=\mathrm{dy} / \mathrm{dt}=\mathrm{y}(\mathrm{U} 21-\mathrm{U} 2)=\mathrm{y}(1-\mathrm{y})\{\mathrm{F}-\mathrm{tC} 0+\mathrm{xts}-\mathrm{xz} \alpha \mathrm{ts}+\mathrm{z}[\mathrm{aR}-$ $(1-\alpha)(\mathrm{tC}-\mathrm{C} 1)+2 \mathrm{tC} 0-\mathrm{L}]\}$

$\mathrm{F}(\mathrm{z})=\mathrm{dz} / \mathrm{dt}=\mathrm{z}(\mathrm{U} 31-\mathrm{U} 3)=\mathrm{z}(1-\mathrm{z})\{\mathrm{F}-(1-\mathrm{t}) \mathrm{C} 0+\mathrm{x}[\mathrm{G} 2+(1-$

t)S $+y[(1-a) R-L-(1-t)(C-2 C 0)+C 2]\}$

Therefore, if $\mathrm{F}(\mathrm{x})=0, \mathrm{~F}(\mathrm{y})=0, \mathrm{~F}(\mathrm{z})=0$, the following local equilibrium points can be obtained: $\mathrm{E} 1(0,0,0)$, E2 $(0,0,1)$, E3 $(0,1,0), \mathrm{E} 4(0,1,1), \mathrm{E} 5(1,0,0), \mathrm{E} 6(1,0,1)$, $\mathrm{E} 7(1,1,0), \mathrm{E} 8(1,1,1)$

According to the method proposed by Friedman, the evolutionary stabilization strategy of the differential equation system can be obtained from the local stability analysis of the Jacobian matrix of the system [10], and the Jacobian matrix of the system obtained from the abovementioned replication dynamic system is as follows:

$-\mathrm{x}(1-\mathrm{x}) \mathrm{G} 2$

$\mathrm{y}(1-\mathrm{y})[\mathrm{aR}-(1-\alpha)(\mathrm{tC}-\mathrm{C} 1)+2 \mathrm{tC} 0-\mathrm{L}-\mathrm{x} \alpha \mathrm{ts}]$

$(1-2 \mathrm{z})\{\mathrm{F}-(1-\mathrm{t}) \mathrm{C} 0+\mathrm{x}[\mathrm{G} 2+(1-\mathrm{t}) \mathrm{S}]+\mathrm{y}[(1-\mathrm{a}) \mathrm{R}-\mathrm{L}-(1-\mathrm{t})(\mathrm{C}-$ $2 \mathrm{C} 0)+\mathrm{C} 2]\}$

\subsection{Stability analysis}

equilibrium points in the game's replication dynamic system. The eigenvalues of the local equilibrium points are shown in Table 3 below:

From the above analysis, we can see that there are 8 local

Table3. Eigenvalues of the Jacobian matrix

\begin{tabular}{|c|c|c|c|}
\hline Local equilibrium point & Characteristic value 1 & Characteristic value 2 & Characteristic value 3 \\
\hline $\mathrm{E} 1(0,0,0)$ & (1-b)R1-G1 & F-tC0 & $\mathrm{F}-(1-\mathrm{t}) \mathrm{C} 0$ \\
\hline $\mathrm{E} 2(0,0,1)$ & (1-b)R1-G1-G2 & $\mathrm{F}+\mathrm{aR}-\mathrm{L}+\mathrm{tC} 0-(1-\alpha)(\mathrm{tC}-\mathrm{C} 1)$ & $-[\mathrm{F}-(1-\mathrm{t}) \mathrm{C} 0]$ \\
\hline $\mathrm{E} 3(0,1,0)$ & (1-b)R1-G1 & $-(\mathrm{F}-\mathrm{tC} 0)$ & $\mathrm{F}+(1-\mathrm{a}) \mathrm{R}-\mathrm{L}-(1-\mathrm{t})(\mathrm{C}-\mathrm{C} 0)+\mathrm{C} 2$ \\
\hline $\mathrm{E} 4(0,1,1)$ & (1-b)R1-G1-G2 & $-[\mathrm{F}+\mathrm{aR}-\mathrm{L}+\mathrm{tC} 0-(1-\alpha)(\mathrm{tC}-\mathrm{C} 1)]$ & $-[\mathrm{F}+(1-\mathrm{a}) \mathrm{R}-\mathrm{L}-(1-\mathrm{t})(\mathrm{C}-\mathrm{C} 0)+\mathrm{C} 2]$ \\
\hline $\mathrm{E} 5(1,0,0)$ & $-[(1-b) R 1-G 1]$ & F-t $(\mathrm{C} 0-\mathrm{S})$ & $\mathrm{F}+\mathrm{G} 2-(1-\mathrm{t})(\mathrm{C} 0-\mathrm{S})$ \\
\hline E6(1,0,1) & $-[(1-b) R 1-G 1-G 2]$ & $\mathrm{F}+\mathrm{aR}-\mathrm{L}+\mathrm{tC} 0-(1-\alpha)(\mathrm{tC}-\mathrm{C} 1-\mathrm{tS})$ & $-[\mathrm{F}+\mathrm{G} 2-(1-\mathrm{t})(\mathrm{C} 0-\mathrm{S})]$ \\
\hline$\overline{E 7}(1,1,0)$ & $-[(1-b) R 1-G 1]$ & $-[\mathrm{F}-\mathrm{t}(\mathrm{C} 0-\mathrm{S})]$ & $\mathrm{F}+\mathrm{G} 2+(1-\mathrm{a}) \mathrm{R}-\mathrm{L}-(1-\mathrm{t})(\mathrm{C}-\mathrm{C} 0-\mathrm{S})+\mathrm{C} 2$ \\
\hline $\mathrm{E} 8(1,1,1)$ & $-[(1-b) R 1-G 1-G 2]$ & $-[\mathrm{F}+\mathrm{aR}-\mathrm{L}+\mathrm{tC} 0-(1-\alpha)(\mathrm{tC}-\mathrm{C} 1-\mathrm{tS})]$ & $-[\mathrm{F}+\mathrm{G} 2+(1-\mathrm{a}) \mathrm{R}-\mathrm{L}-(1-\mathrm{t})(\mathrm{C}-\mathrm{C} 0-\mathrm{S})+\mathrm{C} 2]$ \\
\hline
\end{tabular}

In order to facilitate the analysis of the sign of the eigenvalues corresponding to the above equilibrium points, and without loss of generality, it is assumed that the net income of the government, enterprises, and research institutes participating in the cooperative strategy in the game is greater than the net income of not participating in the cooperation. Mathematically expressed as: (1-b) R1G1-G2 $>0$; F+aR-L- $(1-\alpha)(\mathrm{tC}-\mathrm{C} 1)+\mathrm{C} 0>0 ; \mathrm{F}+(1-\mathrm{a}) \mathrm{RL}-(1-$ $\mathrm{t})(\mathrm{C}-\mathrm{C} 0)+\mathrm{C} 2>0$. Analyze the stability of the above equilibrium point in different situations:

Scenario 1: F-(1-t) $\mathrm{C} 0>0$ or $\mathrm{F}-\mathrm{tC} 0>0$. The stability analysis of the above 8 local equilibrium points in case 1 is shown in Table 4 below. From Table 4, it can be obtained that only E8 satisfies all the eigenvalues of the Jacobian matrix, so in case 1, E8 is ESS, the corresponding evolutionary stability strategy is (participation, participation, participation).
Table4. Equilibrium point stability in case 1

\begin{tabular}{|l|l|l|l|l|}
\hline & value 1 & value 2 & value 3 & Stability \\
\hline E1 $(0,0,0)$ & + & + & + & Saddle point \\
\hline E2(0,0,1) & + & + & - & Unstable point \\
\hline E3(0,1,0) & + & - & + & Unstable point \\
\hline E4 $(0,1,1)$ & + & - & - & Unstable point \\
\hline E5(1,0,0) & - & + & + & Unstable point \\
\hline E6(1,0,1) & - & + & - & Unstable point \\
\hline E7(1,1,0) & - & - & + & Unstable point \\
\hline E8(1,1,1) & - & - & - & ESS \\
\hline
\end{tabular}

Scenario 2: $\mathrm{F}+\mathrm{G} 2-(1-\mathrm{t})(\mathrm{C} 0-\mathrm{S})<0$ and $\mathrm{Ft}(\mathrm{C} 0-\mathrm{S})<0$. The stability analysis of the above 8 local equilibrium points in case 2 is shown in Table 5 below. From Table 5, it can be obtained that all the eigenvalues of E5 and E8 satisfying the Jacobian matrix are non-positive, so in case 2, E5, E8 is ESS, and its corresponding evolutionary stability strategies are (participate, not participate, not participate), (participate, participate, participate). 
Table5. Equilibrium point stability in case 2

\begin{tabular}{|l|l|l|l|l|}
\hline & value 1 & value 2 & value 3 & Stability \\
\hline E1 $(0,0,0)$ & + & - &,+- & Unstable point \\
\hline E2(0,0,1) & + & + &,+- & Saddle point \\
\hline E3(0,1,0) & + & + & + & Saddle point \\
\hline E4(0,1,1) & + & - & - & Unstable point \\
\hline E5(1,0,0) & - & - & - & ESS \\
\hline E6(1,0,1) & - & + & + & Unstable point \\
\hline E7(1,1,0) & - & + & + & Unstable point \\
\hline E8(1,1,1) & - & - & - & ESS \\
\hline
\end{tabular}

Scenario 3: F-tC $0<0$ and $\mathrm{Ft}(\mathrm{C} 0-\mathrm{S})>0$; or $\mathrm{F}-(1-\mathrm{t}) \mathrm{C} 0<0$ and $\mathrm{F}+\mathrm{G} 2-(1-\mathrm{t})(\mathrm{C} 0-\mathrm{S})>0$. The stability analysis of the above 8 local equilibrium points in case 3 is shown in Table 6 below. From Table 6, it can be obtained that only E8 satisfies all the eigenvalues of the Jacobian matrix, so in case 3, E8 is ESS, The corresponding evolutionary stability strategy is (participation, participation, participation).

Table6. Equilibrium point stability in case 3

\begin{tabular}{|l|l|l|l|l|}
\hline & vable6. & vquilibrium point stability in case 3 \\
\hline E1 $(0,0,0)$ & + & - & - & Unstable point \\
\hline E2(0,0,1) & + & + & + & Saddle point \\
\hline E3 $(0,1,0)$ & + & + & + & Saddle point \\
\hline E4(0,1,1) & + & - & - & Unstable point \\
\hline E5 $(1,0,0)$ & - & + & + & Unstable point \\
\hline E6 $(1,0,1)$ & - & + & - & Unstable point \\
\hline E7(1,1,0) & - & - & + & Unstable point \\
\hline E8(1,1,1) & - & - & - & ESS \\
\hline
\end{tabular}

\section{4 conclusions}

By establishing a green innovation game model of government, enterprise, research, and research, this paper analyzes the robust strategy in different situations. From the game process, it can be seen that whether enterprises and the research and development parties participate in green innovation cooperation depends on government policy support, resource costs, and Excessive earnings and fines for breach of contract.

\subsection{Incentive and punishment mechanism go hand in hand}

It can be seen from the game process that when the government increases policy support or improves supervision and management standards, the willingness of enterprises and academic research parties to cooperate in green innovation will also increase. The role of the government in green innovation cooperation needs to be strengthened: on the one hand, the government should actively guide enterprises and academic research parties to participate in green innovation cooperation by formulating financial support policies, tax preferential policies, establishing basic public platforms, etc. Social atmosphere; on the other hand, the government should actively exercise the responsibility of the regulator, establish a legal system to solve the problem of unequal distribution of income, and give economic penalties to the breaching party to increase the cost of breaching the contract, thereby improving the efficiency of green innovation cooperation between the enterprise and the academic research side.

\subsection{Improve the safety of green innovation cooperation}

Enterprises and academic research parties need to communicate and cooperate with other external parties in the process of participating in green innovation cooperation, but due to the asymmetry and lag of access to information, the uncertainty and risk of green innovation cooperation have increased. Therefore, the government can ensure the transparency of information in the process of green innovation by building high-tech industrial parks, using big data and other technologies to build information exchange platforms, and reduce the loss caused by poor information, providing powerful cooperation for green innovation cooperation between enterprises and academic institutions. Support and guarantee.

\subsection{Construct a reasonable excess income distribution ratio}

The direct driving force for green innovation between enterprises and academic research institutes is to pursue higher interests, and a reasonable ratio of profit distribution will promote further cooperation and cooperation stability. Therefore, on the basis of comprehensively measuring the cost of the input of resource elements, innovation capacity and willingness of the enterprise and the academic research side, the level of risk taken, etc., and referring to the opinions of professional third-party evaluation agencies to determine a scientific and reasonable excess The proportion of income distribution, and then the rational distribution of excess income, enable the green innovation cooperation between enterprises and academic institutions to continue to develop steadily.

\section{Acknowledgement:}

This work is partially supported by National Social Science Foundation of China No. 16BGL021. The authors also gratefully acknowledge the helpful comments and suggestions of the reviewers, which have improved the presentation.

\section{References}

1. Deng Feng Game between the Government and Enterprise Under Incompletely Implemented Regulations of Pollution[J]. Forecasting, 2008, 27(1):67-71.

2. Cao Xia, Zhang Lupeng. Evolutionary Game Analysis of Enterprise Green Technology Innovation under Environmental Regulation-Based on Stakeholder Perspective[J]. System Engineering, 2017(2):103-108.

3. Xu Jianzhong, Guan Jun, Zhu Xiaoya. Evolutionary Game Research on the Influence of Government Behavior on the Selection of Green Innovation Models in Manufacturing Enterprises[J]. Operations Research and Management, 2017(9): 68-77. 
4. Nie Aiyun, He Xiaogang. Corporate green technology innovation: environmental regulation and policy combination [J]. Reform, 2012 (4): 102-108.

5. Etzkowitz H. Entrepreneurial scientists and entrepreneurial universities in American academic science[J]. Minerva,1983:198-233.

6. Cao Xia, Yu Juan. Research on the stability of industry-university-research innovation alliance based on government governance [J]. Journal of System Management, 2017, 26(5): 916-925.

7. Zang Xinyu, Ma Yonghong. Research on Decision Mechanism of Industry-University-Research Cooperation Behavior from the Perspective of Collaborative Innovation $[\mathrm{J}]$. Operations Research and Management, 2018, 27(3)93-103.

8. CHESBROUGH H, PRENCIPE A. Networks of innovation and modularity: a dynamic perspective[J]. International Journal of Technology Management,2008,42(4):414-425.

9. Wang Huange. Research on Evolutionary Game of Collaborative Innovation of Low-Carbon Technology of Industry, University and Research Institute [D]. North China Electric Power University, 2019.

10. Zhao Leiying. Research on Performance Evaluation and Influencing Factors of Collaborative Innovation of Industry, University and Research Institute [D]. China University of Mining and Technology, 2016.

11. Friedman D. Evolutionary games in economics [J]. Econometrica, 1991, 59(3): 637-666. 